\title{
CONVERSAÇÕES ENTRE A REDE SOCIAL TWITTER E OS ARQUIVOS PERMANENTES: UM ESTUDO DE CURADORIA DIGITAL
}

\author{
CONVERSACIONES ENTRE TWITTER SOCIAL MEDIA Y \\ HISTORICAL ARCHIVES: UN ESTUDIO DE CURACIÓN \\ DIGITAL
}

\author{
Maria José Vicentini Jorente* \\ Lucineia da Silva Batista**
}

\begin{abstract}
RESUMO
Introdução: A Curadoria Digital, convergente ao Design da Informação (DI), cria novas estratégias interativas de compartilhamento da informação para os Arquivos Públicos Permanentes (APP); entre tais estratégias, a interação dessas disciplinas pode facilitar o entendimento do desenho de mídias sociais da Web 2.0, como o Twitter, que se propõe com estrutura própria para a implementação de ações culturais de caráter pós-custodial em extensões dos APP em ambiências digitais. Objetivos: Apresentar e sugerir iniciativas inovadoras de Curadoria Digital no Twitter para compartilhamento de informações preservadas pelos APP. Metodologia: pesquisa teórica e exploratória na perspectiva das interdisciplinaridades da Ciência da Informação $(\mathrm{Cl})$. No estágio exploratório, a pesquisa verifica a convergência do Twitter em ambientes digitais de 10 APP em que com o Twitter e as estratégias de Curadoria Digital empregadas em dois (02) dos mais relevantes, concluindo inadequadas para a contemporaneidade. Resultados: apresenta iniciativas e sugestões que o Twitter oferece aos Arquivos, em ações culturais organizadas pelo DI e caracterizadas como de Curadoria Digital como a de narrações de eventos históricos, concomitantemente à publicação de documentos de acervo digitalizado e custodiado fisicamente pela instituição. Conclusões: A Curadoria Digital emerge como estratégia pós-custodial das atuações dos profissionais da informação nos APP.
\end{abstract}

Palavras-chave: Tecnologia da Informação e Comunicação. Design da Informação. Curadoria Digital. Arquivos Permanentes. Twitter.

\footnotetext{
* Doutora em Ciência da Informação Professora do Programa Departamento de Ciência da Informação da Universidade Estadual Paulista Júlio de Mesquita Filho - Marília. E-mail: mjjorente@yahoo.com.br.

** Mestranda do programa de Pós-Graduação em Ciência da Informação pela Universidade Estadual Paulista Júlio de Mesquita Filho - Marília. E-mail: lucineia.bat@gmail.com.
} 


\section{INTRODUÇÃO}

O uso das tecnologias tem facilitado a produção, a organização, o acesso e a disseminação da informação presente em ambientes arquivísticos. A transformação das Tecnologias de Informação e Comunicação (TIC) mudou uma sociedade que até meados do século $X X$ era baseada somente no paradigma do papel (CRUZ MUNDET, 2001). A partir da introdução dos suportes eletrônicos no compartilhamento da informação apresentou-se uma nova realidade que exige o conhecimento e apropriação dos seus meios: o aparecimento dos documentos digitais. Surgiram novas conceituações e aplicações que devem ser consideradas nos processos arquivísticos, pois tanto os profissionais da informação e quanto os não especialistas se deparam atualmente com documentos híbridos (físicos e digitais).

A confluência de mídias e redes sociais digitais no compartilhamento de ativos informacionais custodiados em arquivos e museus, bem como a integração desses ativos surgem como possibilidades para a ação cultural, uma área pouco percebida nas instituições de arquivos, de ênfase custodiadora preservacionista. A abertura, se de um lado aponta para avanços consideráveis, de outro, apresenta problemas críticos, relevantes para a Ciência da Informação $(\mathrm{Cl})$ e que devem ser estudados no âmbito da apresentação das informações nesses ambientes e plataformas digitais. Entre as hipóteses levantadas para a solução dos novos desafios apresentados nestes ambientes encontra-se a Curadoria Digital.

A Curadoria Digital na arquivística está relacionada com a gestão de documentos digitais no ciclo de vida do documento, que vai desde sua criação até sua guarda permanente ou seu descarte, principalmente na preservação de dados em repositórios. Segundo Abbott (2008, [s. p.], tradução nossa):

Todas as atividades envolvidas em gestão de dados de planejamento de sua criação, melhores práticas em digitalização e documentação, e garantir sua disponibilidade e capacidade para descoberta e re-uso no futuro são partes da Curadoria Digital. Curadoria Digital pode também incluir gestão de grande conjunto de dados para uso diário, por exemplo 
garantir que eles possam ser pesquisados e continuem a serem lidos. Curadoria Digital é, portanto, aplicável a uma grande variedade de situações profissionais do começo do ciclo de vida informacional ao fim; digitalizadores, criadores de metadados, financiadores, formuladores de políticas, e gestores de repositórios para citar alguns exemplos.

No panorama nacional, Sayão e Sales em 2012, definem Curadoria Digital como "os conhecimentos e as práticas acumulados na última década em preservação e acesso a recursos digitais resultaram num conjunto de estratégias, abordagens tecnológicas e atividades que agora são coletivamente conhecidas como "curadoria digital” (SAYÃO; SALES, 2012, p. 184).

Também afirmam em seu texto de 2012 que o conceito está em constante evolução, embora entendamos que em 2017 já possamos falar em consolidação:

Ainda que seja um conceito em evolução, já está estabelecido que a curadoria digital envolve a gestão atuante e a preservação de recursos digitais durante todo o ciclo de vida de interesse do mundo acadêmico e científico, tendo como perspectiva o desafio temporal de atender a gerações atuais e futuras de usuários. (SAYÃO; SALES, 2012, p. 184).

Neste processo de consolidação, o conceito de Curadoria Digital é acrescido de sentido, pela visão apresentada por Siebra et al. (2013, [s. p.]):

Curadoria Digital como uma área de pesquisa e prática interdisciplinar que reflete uma abordagem holística para o gerenciamento do objeto digital e inclui atividades que abrangem todo o ciclo de vida desse objeto. De acordo com o Digital Curation Center (DCC), a curadoria digital exprime a ideia de manter e agregar valor à informação digital, tanto para uso atual quanto futuro e envolve a gestão ativa e a preservação de recursos digitais durante todo o ciclo de vida do dado digital, enquanto houver interesse do mundo acadêmico e científico. A preservação digital passa, então, a ser é entendida como uma etapa no âmbito desse ciclo.

Nesse contexto, diferentemente da perspectiva de Sayão e Sales, Siebra et al. defendem a preservação digital como apenas uma etapa da Curadoria Digital.

A discussão apresentada pelo texto de 2013 acrescenta que, outras etapas do ciclo documental digital também devem ser pensadas sob a 
Maria José Vicentini Jorente; Lucineia da Silva Batista

Conversações entre a rede social twitter e os arquivos permanentes: um estudo de curadoria digital

perspectiva da Curadoria Digital. O presente artigo considera a pertinência da concepção de Siebra et al. e apresenta o quadro de Higgins (2008, p.136), traduzido para o português, em que podem ser visualizadas as variadas etapas do ciclo sob a perspectiva da Curadoria Digital, na figura 1.

Figura 1 - O modelo do Ciclo de vida da Curadoria do DCC.

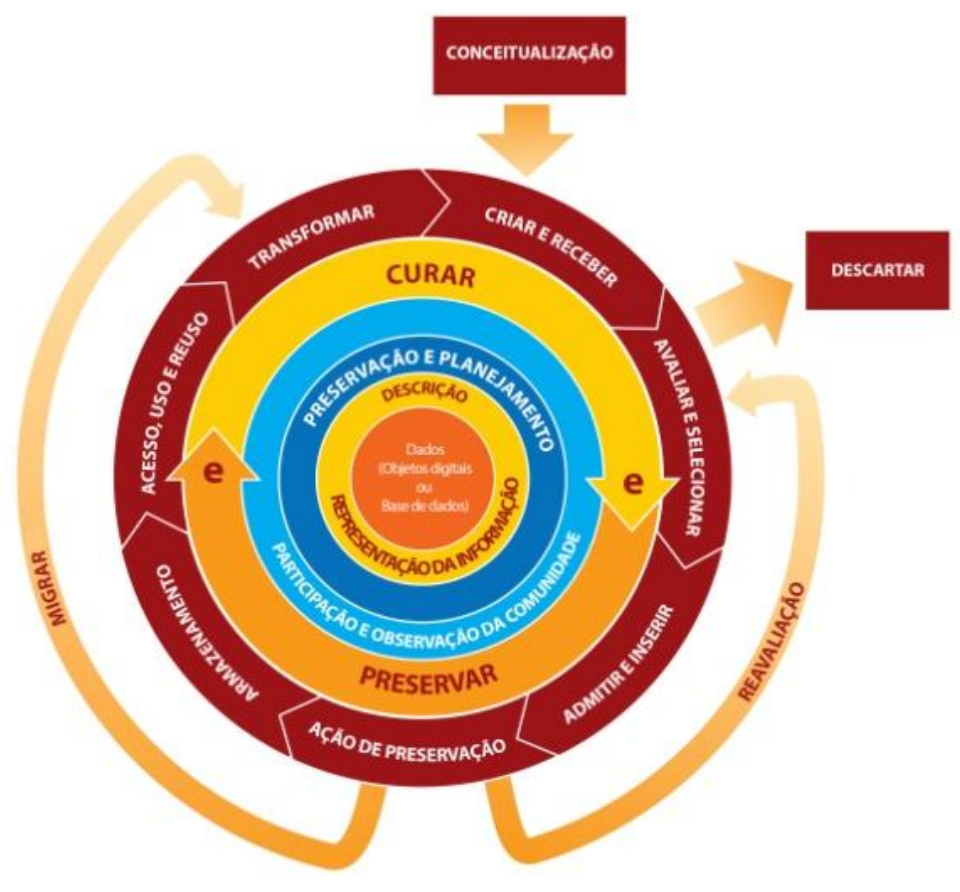

Fonte: Higgins (2008, p. 136, tradução nossa). ${ }^{1}$

Conforme a figura 1 essas etapas devem ser visualizadas do centro para a periferia da imagem e são: Descrição e representação da informação, Planejamento da preservação, Acompanhamento e participação da comunidade, Curadoria e preservação. Para cada uma dessas etapas as ações de curadoria diferem e devem atuar sobre o documento de forma específica. O Design da Informação (DI) pode ser entendido como uma disciplina essencialmente auxiliar na organização de cada uma dessas ações.

${ }^{1}$ A utilização da figura foi autorizada ao LADRI e as autoras pela Universidade de Edimburgo, sua proprietária. 
Nossa pesquisa tratou das possibilidades relacionadas a etapa de acompanhamento e participação da comunidade suportadas nas mídias sociais, visualizável em azul ciam na figura. No presente texto, em particular, dadas as limitações de um trabalho dessa natureza, enfocaremos o Twitter, cujas limitações de número de caracteres (140, na época da pesquisa que resultou neste artigo), imprimem características próprias de compartilhamento de informação que fazem o ambiente particularmente interessante para a área da Cl.

Nessa etapa de acompanhamento e participação da comunidade sugerimos ênfase na

[...] necessidade de atenção para as atividades que se desenrolam no âmbito das comunidades envolvidas com o problema de curadoria, bem como a necessidade de participação no desenvolvimento de padrões, de ferramentas e de software adequados ao problema e que possam também serem compartilhados. (SIEBRA et al., 2013, [s. p.]).

Por tal razão, a metodologia adotada constituiu-se de levantamento teórico somado à pesquisa exploratória, fase em que se destaca o contexto brasileiro, sobre a aplicação da rede social Twitter na perspectiva da Curadoria Digital, como área emergente da $\mathrm{Cl}$. Foi realizada na segunda fase, portanto, pesquisa exploratória, com levantamento quanti-qualitativo em 10 Arquivos Públicos Permanentes brasileiros, nos quais se verificou, primeiramente, a convergência da rede Twitter. Sequencialmente, optamos por investigar qualitativamente dois desses ambientes, por um critério de relevância, acompanhando o fluxo de vinte tweets cada. Para o estudo que trazemos para este artigo selecionamos, assim, o Arquivo Público do Estado de São Paulo e o Arquivo Público Estado do Rio Grande do Sul realizando uma análise de Curadoria de Conteúdo, uma das etapas da Curadoria Digital, e verificando, ao fazê-lo, como os conteúdos informacionais eram postados, a fim de identificar a sua adequação ao meio digital para o compartilhamento das informações de seus acervos na mídia Twitter.

Verificamos principalmente nos ambientes dos Arquivos elencados para a nossa investigação, qual era a tipologia da informação publicada por eles na 
rede Twitter. Posteriormente, comparamos as publicações às requisições das etapas e fases da Curadoria Digital segundo modelo desenvolvido pelo Digital Curation Centre (DCC), sediado em Edimburgo e referência na área.

Apresentamos, então, a título de exemplificação, algumas iniciativas selecionadas em instituições no âmbito do compartilhamento da informação que fizeram ou fazem uso do Twitter. Tais iniciativas podem ser adequadas para o compartilhamento de informações documentais arquivísticas, tais como, narrativas de eventos históricos, realizadas a partir de documentos custodiados nas instituições de guarda permanente. Além disso, destacamos para o entendimento de nossa perspectiva sistêmica e complexa, o número de vezes que um tweet pode ser compartilhado para a demonstração do valor de escalabilidade e alcance da informação quando suportada por uma rede de compartilhamento - utilizada, naturalmente, de forma estratégica, segundo um Design da Informação interdisciplinar, que disponha de ferramentas apropriadas.

Entendemos que a Curadoria Digital de acervos, em geral, e também dos acervos arquivísticos em ambiente digital, proporciona que a informação preservada nos documentos possa ser compartilhada com os internautas que visitam o ambiente e que podem se apropriar dos conteúdos e formas de apresentação da informação que ali visualizam, de maneira a empoderar-se como protagonistas do conhecimento ali representado. Note-se que, para o compartilhamento das informações são necessárias estratégias diversas daquelas utilizadas na disseminação da informação, pois aqui deve-se compreender etapas de horizontalidade, ou bottom-up, nos relacionamentos dos internautas com os ambientes digitais.

Assim, quando os autores do texto apresentado em 2013 no GT8 defendem a "necessidade de atenção para as atividades que se desenrolam no âmbito das comunidades" (SIEBRA et al., 2013, [s. p.]), devemos nos perguntar a que se refere essa necessidade, quanto às atividades desenvolvidas nas comunidades, para quem estamos organizando a informação, sobre e em que suportes ela pode ser organizada com mais eficiência para atender às necessidades dos que necessitam da informação. 
O levantamento de hipóteses que responde a essa necessidade sugere como uma forte resposta que os Arquivos Públicos, de maneira especial, devem se utilizar de Repositórios Digitais com o acesso facilitado e neles realizar Curadoria Digital dos acervos, considerando cada uma das etapas com o fim de, não somente preservar e dar acesso à informação, mas também para promover o encontro entre diversas culturas nos contextos de diversidades que se colocam em todas as sociedades humanas.

Em segundo lugar, devemos repensar o ciclo dos documentos custodiados desde a primeira etapa, ou seja, na descrição e representação da informação. Nesse sentido, a conceitualização deve se traduzir em métodos e estratégias elaboradas pelos profissionais da informação, primeiramente na etapa de "Conceber e planejar a criação do dado, incluindo os métodos de captura e as opções de armazenamento" (SIEBRA et al., 2013, [s. p.]). As estratégias devem levar em conta as políticas informacionais de compartilhamento, públicas e institucionais, bem como os contextos de compartilhamento.

A etapa de Criação e/ou Recebimento de um acervo e o seu entendimento como um sistema complexo do que possui valor para determinada ou determinadas comunidades implica em

Criar dados, incluindo metadados administrativos, descritivos, estruturais e técnicos. Metadados de preservação podem, também, serem adicionados no momento da criação. Receber dados, de acordo com políticas bem documentadas, de criadores de dados, de outros arquivos, de repositórios ou de centros de dados e, se necessário atribuir metadados apropriados. (SIEBRA et al., 2013, [s. p.]).

A etapa de Avaliação e Seleção do que deve ser representado no ambiente digital, a partir do acervo total da instituição, também deve ser objeto de reflexão e cura em que é necessário "Avaliar o dado e selecionar o que será objeto dos processos de curadoria e de preservação por longo prazo, bem como, manter-se aderente tanto às boas práticas quanto às políticas pertinentes e também às exigências legais" (SIEBRA et al., 2013, [s. p.]). Em se tratando de arquivos que foram produzidos em papel, suportes que 
atualmente prevalecem no atual estágio dos Arquivos Públicos Permanentes no Brasil, principalmente, a migração para o ambiente digital deve ser seletiva e afinada com as estratégias traçadas por equipe multidisciplinar de profissionais, para que o compartilhamento da informação se faça concomitantemente com a migração a fim de que essas duas ações se harmonizem durante o processo.

A essas conceituações e procedimentos se denomina Curadoria Digital e as estratégias utilizadas devem ser pensadas a partir das sub-disciplinas, metodologias e ferramentas do DI. O arquivamento no ambiente digital será, assim, seletivo e feito de acordo com ações culturais, pensadas como Curadoria.

Passamos, dessa forma, a falar de ação cultural no âmbito dos Arquivos Públicos Permanentes (APP), uma perspectiva até o momento alheia, de maneira geral, ao universo arquivístico; porém, importante componente de uma nova realidade, na qual os APP devem ser revisitados como espaços de memórias, cujos fragmentos podem ser organizados e reorganizados de múltiplas maneiras. Ou seja, a transferência de dados para um Arquivo, Repositório, Centro de Dados ou outro custodiador digital passa por ações de Curadoria e de $D \mathrm{I}$ diversas das presenciais, e que podem se reconfigurar para atender a contextos diversos.

Quanto a "[...] necessidade de participação no desenvolvimento de padrões, de ferramentas e de software adequados ao problema e que possam também serem compartilhados"(SIEBRA et al., 2013, [s. p.]), sugerimos que para atender a esse requisito, seja usados softwares livres e abertos, que suportem a participação daqueles para os quais a curadoria está destinada, pois, uma das tarefas do Arquivo, além de preservação e disponibilização presencial dos documentos, é a do compartilhamento da informação em ambientes digitais, que rompam com as barreiras tradicionais de acesso à informação.

Quanto a essas afirmações, devemos fazer uma reflexão em relação a nomenclatura e conceito tradicional de disseminação, ligado ao paradigma tecnicista e operacional moderno. Esse paradigma e a nomenclatura que o 
traduz devem ser questionados, pois, em um sistema complexo, no qual os indivíduos são também protagonistas da informação, disseminação nos parece ainda um termo que induz a pensar em um emissor ativo e um receptor passivo da informação, uma prática de curadoria da informação na perspectiva de um para muitos.

Há urgência na reflexão e mudanças, pois embora alguns APP eventualmente se utilizem de redes sociais, o fazem da perspectiva da difusão - pouquíssimos são os APP que inserem em suas políticas e práticas a curadoria ampliada, ou pós-custodial, que considera todas as etapas em que são exigidas ações culturais idealizadas determinadas. A maioria atua na mera difusão de seus catálogos, guias, inventários, boletim informativo, instrumentos de pesquisa em geral, quando o fazem.

No Brasil, de acordo com o trabalho de dissertação de mestrado realizado em 2013 (GONÇALEZ, 2013) verificou-se que de 26 estados brasileiros, apenas 17 haviam adequado-se à Lei de Acesso à Informação (LAI) promulgada em 2011, e disponibilizado ambientes digitais para consulta a distancia de seus arquivos. Posteriormente, um diagnóstico ampliado, realizado em projeto PIBIC por uma das autoras deste artigo e relacionado aos municípios do país com mais de 100.000 habitantes - condição que os tornava de acordo com a LAI obrigados a disponibilizar informações de seu acervo em ambientes digitais - apresentou um quadro ainda mais preocupante. Os resultados mostraram assim que os poucos Arquivos Públicos, estaduais ou municipais, que disponibilizavam a informação de seus acervos online não levavam em consideração a Curadoria Digital e as possibilidades expandidas da Web Social 2.0, limitando-se as funções mínimas de difusão.

Os Arquivos brasileiros, principalmente os municipais, apresentam, portanto, atrasos significativos tanto em relação à Curadoria Digital quanto à preservação e também quanto ao acesso e compartilhamento em ambiente digital. A pesquisa que deu origem a este artigo verificou que, dos 16 Arquivos Públicos Estaduais identificados com alguma página ou Website, sete usam o Twitter e nove usam o Facebook. Outros sete desses APP usam as duas redes para uma melhor aproximação dos internautas e compartilhamento de 
Maria José Vicentini Jorente; Lucineia da Silva Batista

Conversações entre a rede social twitter e os arquivos permanentes: um estudo de curadoria digital

informações variadas. Por outro lado, destacamos uma quantidade significativa de sete APP que não usam nenhuma dessas redes sociais, ${ }^{2}$.

$\mathrm{Na}$ segunda etapa da pesquisa, a partir do levantamento realizado nos 16 APP, foi escolhido o Arquivo Público do Estado de São Paulo (APESP) para verificar a natureza da Curadoria Digital dos conteúdos compartilhados pela instituição da rede Twitter. Localizado na região Sudeste do país, em São Paulo, o APESP tem se preocupado em utilizar as TIC, segundo políticas institucionais em que as redes sociais são convergidas no ambiente digital da instituição para contato com os internautas. Assim, foram selecionados os 20 tweets, sequencialmente, publicados no período de 13 de Fevereiro de 2017 à 02 de Março de 2017, para verificar qual o conteúdo informacional postado no Twitter pelo APESP. As informações coletadas estão estruturadas no quadro 1:

Quadro 1 - Tweets publicados no perfil do Arquivo Público do Estado de São Paulo de 2017.

\begin{tabular}{|c|c|c|}
\hline \multicolumn{2}{|c|}{$\begin{array}{l}\text { Data de } \\
\text { Publicação }\end{array}$} & Tweets \\
\hline 01 & $02 / 03 / 2017$ & As inscrições para a oficina de Paleografia terminam amanhã! \\
\hline 02 & $01 / 03 / 2017$ & $\begin{array}{l}\text { Parabenizando a cidade do Rio de Janeiro: hoje a } \\
\text { \#cidademaravilhosa completa } 452 \text { anos. }\end{array}$ \\
\hline 03 & $24 / 02 / 2017$ & $\begin{array}{l}\text { Estão prontos pra folia? Capa da revista A Cigarra, de } \\
15 / 02 / 1922 \text {.Esta e outras edições no acervo digitalizado }\end{array}$ \\
\hline 04 & $24 / 02 / 2017$ & $\begin{array}{l}\text { Comunicado da não abertura do Arquivo no dia } 27 \text { e } 28 \text { de } \\
\text { Fevereiro. }\end{array}$ \\
\hline 05 & $23 / 02 / 2017$ & $\begin{array}{l}\text { A gestão dos documentos públicos garante maior controle da } \\
\text { informação que os órgãos do Estado produzem e recebem. }\end{array}$ \\
\hline 06 & $22 / 02 / 2017$ & $\begin{array}{l}\text { Inscrições abertas para oficina de Paleografia no } \\
\text { @ArquivoPublico. }\end{array}$ \\
\hline 07 & $21 / 02 / 2017$ & $\begin{array}{l}\text { Este documento é uma matrícula geral dos colonos, do Núcleo } \\
\text { Colonial de São Bernardo (1887 a 1892). }\end{array}$ \\
\hline 08 & $21 / 02 / 2017$ & $\begin{array}{l}\text { Dia } 21 \text { de fevereiro é marcado pela comemoração da chegada } \\
\text { dos \#imigrantesitalianos no Brasil. }\end{array}$ \\
\hline 09 & $20 / 02 / 2017$ & Exposição 'Diários Associados' está aberta para visitação! \\
\hline 10 & $20 / 02 / 2017$ & $\begin{array}{l}\text { Em breve haverá oficina de Paleografia no Arquivo Público, } \\
\text { com técnicas de leitura e transcrição de documentos } \\
\text { manuscritos. Aguardem! }\end{array}$ \\
\hline
\end{tabular}

2 BATISTA, L. S. Arquivos permanentes: um estudo de caso no Twitter. 2012. 86 f. Trabalho de Conclusão de Curso (Bacharelado em Arquivologia) - Universidade Estadual Paulista, Faculdade de Filosofia e Ciências de Marília, Marília, 2012. 
Maria José Vicentini Jorente; Lucineia da Silva Batista

Conversações entre a rede social twitter e os arquivos permanentes: um estudo de curadoria digital

\begin{tabular}{|c|c|c|}
\hline 11 & $16 / 02 / 2017$ & Hoje é o \#DianacionaldoReporter. \\
\hline 12 & $16 / 02 / 2017$ & $\begin{array}{l}\text { "Arquivo do Estado e a preservação da memória paulista" é o } \\
\text { tema do Programa Conversações. }\end{array}$ \\
\hline 13 & $15 / 02 / 2017$ & $\begin{array}{l}\text { Com ICA-AtoM, o pesquisador tem uma visão geral do fundo, } \\
\text { do conteúdo e do contexto em que a documentação foi } \\
\text { gerada. }\end{array}$ \\
\hline 14 & $15 / 02 / 2017$ & $\begin{array}{l}\text { O APESP é uma das } 250 \text { instituições que aderiram o ICA- } \\
\text { AtoM como plataforma p/ Guia do Acervo }\end{array}$ \\
\hline 15 & $14 / 02 / 2017$ & $\begin{array}{l}\text { A técnica Lilian explicou que este processo funciona como um } \\
\text { "quebra-cabeça": cada fragmentos soltos serão realocados c/ } \\
\text { uma fita termostática. }\end{array}$ \\
\hline 16 & $14 / 02 / 2017$ & $\begin{array}{l}\text { Veja na imagem que algumas páginas do livro estão } \\
\text { fragmentadas devido ações do tempo, acidez do papel e o } \\
\text { manuseio intenso das folhas. }\end{array}$ \\
\hline 17 & $14 / 02 / 2017$ & $\begin{array}{l}\text { O Núcleo de Conservação do Arquivo Público iniciou } \\
\text { recentemente o trabalho de recuperação do livro de "Matricula } \\
\text { de Immigrantes" de } 1895 \text {. }\end{array}$ \\
\hline 18 & $14 / 02 / 2017$ & $\begin{array}{l}\text { Acervo digital: o site do @ArquivoPublico reúne mais de } 400 \\
\text { mil imagens de documentos digitalizados. }\end{array}$ \\
\hline 19 & $13 / 02 / 2017$ & O hoje, 13 de fevereiro, é celebrado o Dia Mundial do Rádio. \\
\hline 20 & $13 / 02 / 2017$ & $\begin{array}{l}\text { Acervo fotográfico sobre a vida pública e familiar de Mario } \\
\text { Covas está online. }\end{array}$ \\
\hline
\end{tabular}

Fonte: os próprios autores.

A segunda instituição arquivística escolhida foi o Arquivo Público do Estado do Rio Grande do Sul (APERS) para verificar o uso que têm feito do Twitter. O APRS está localizado na região Sul do país. O APP tem se preocupado em acompanhar a tecnologia, sendo as redes sociais um dos recursos usados para contato com o público/usuários. No ambiente também foram selecionados 20 tweets, sequencialmente, publicados no período de 02 de março de 2017 à 03 de Março de 2017, para verificar qual o conteúdo informacional postado no Twitter pelo APERS. As informações coletadas estão estruturadas no quadro 2:

Quadro 2 - Tweets publicados no perfil do Arquivo Público do Rio Grande do Sul no ano de 2017.

\begin{tabular}{|l|l|l|}
\hline $\begin{array}{l}\text { Data de } \\
\text { Publicação }\end{array}$ & Tweets \\
\hline 01 & $03 / 03 / 2017$ & Assista ao vídeo institucional do Arquivo \\
\hline 02 & $03 / 03 / 2017$ & Dicas de Séries: Mundo dos Arquivos - parte 1 \\
\hline 03 & $03 / 03 / 2017$ & Exposição Trabalhadoras Mulheres no Arquivo \\
\hline 04 & $03 / 03 / 2017$ & Dicas de Séries: Mundo dos Arquivos - parte 2 \\
\hline 05 & $03 / 03 / 2017$ & Atividades do SIARQ/RS \\
\hline 06 & $03 / 03 / 2017$ & Divulga APERS: artigos a serem publicados esse ano \\
\hline
\end{tabular}


Maria José Vicentini Jorente; Lucineia da Silva Batista

Conversações entre a rede social twitter e os arquivos permanentes: um estudo de curadoria digital

\begin{tabular}{|c|c|c|}
\hline 07 & 03/03/2017 & Dica: cartilha sobre Lei de Acesso à Informação \\
\hline 08 & 03/03/2017 & $\begin{array}{l}\text { APERS conta história: relatórios de instituições prisionais do } \\
\text { interior do Estado. }\end{array}$ \\
\hline 09 & $03 / 03 / 2017$ & $\begin{array}{l}\text { Documentos da escravidão >> Catálogo Seletivo dos } \\
\text { Processos Crimes: o escravo como vítima ou réu: }\end{array}$ \\
\hline 10 & 03/03/2017 & $\begin{array}{l}\text { APERS conta histórias: A implantação de Arquivos } \\
\text { Intermediários no RS }\end{array}$ \\
\hline 11 & 02/03/2017 & $\begin{array}{l}\text { Convite: dia } 8 \text { de março, próxima quarta-feira, o Arquivo } \\
\text { Público do RS estará de aniversário: } 111 \text { anos! Venha } \\
\text { celebrar... }\end{array}$ \\
\hline 12 & 02/03/2017 & $\begin{array}{l}\text { Divulgação: em } 2017 \text { permanecemos com as publicações } \\
\text { de artigos periódicos em nosso blog, confira as temáticas } \\
\text { que serão... }\end{array}$ \\
\hline 13 & 02/03/2017 & $\begin{array}{l}\text { Em fevereiro, houve mais de } 800 \text { atendimentos aos } \\
\text { usuários no APERS, veja este e outros dados no "APERS } \\
\text { em Números" }\end{array}$ \\
\hline 14 & 02/03/2017 & $\begin{array}{l}\text { Confira informações sobre as atividades relacionadas ao } \\
\text { Sistema de Arquivos do RS }\end{array}$ \\
\hline 15 & 02/03/2017 & $\begin{array}{l}\text { Nas segundas-feiras (14h30min) e nas sextas-feiras (10 h) } \\
\text { oferecemos visitas guiadas ao conjunto arquitetônico... }\end{array}$ \\
\hline 16 & 02/03/2017 & $\begin{array}{l}\text { Em fevereiro houve mais de } 800 \text { atendimentos aos usuários } \\
\text { no APERS, veja este e outros dados no "APERS em } \\
\text { Números }\end{array}$ \\
\hline 17 & 02/03/2017 & $\begin{array}{l}\text { APERS } 111 \text { anos: Exposição Trabalhadoras Mulheres no } \\
\text { APERS }\end{array}$ \\
\hline 18 & 02/03/2017 & $\begin{array}{l}\text { Divulga APERS - Novidades, publicações de artigos no } \\
\text { blog. }\end{array}$ \\
\hline 19 & 02/03/2017 & $\begin{array}{l}\text { APERS em Números - Fevereiro 2017, dados estatísticos } \\
\text { de visitas ao Arquivo. }\end{array}$ \\
\hline 20 & 02/03/2017 & Atividades SIARQ/RS - Fevereiro 2017 \\
\hline
\end{tabular}

Fonte: os próprios autores.

Da análise desses conteúdos percebemos que os dois APP têm se esforçado para divulgar informações relevantes para seus seguidores. Os APP Estaduais de São Paulo e do Rio Grande do Sul usam o Twitter para a divulgação de guias, de eventos, de exposições e atividades realizadas pelo Arquivo, de publicações de pesquisas feitas pelo Arquivo e no Arquivo, por pesquisadores; levam ao conhecimento do seguidor acervos que estão disponíveis online, divulgam datas importantes entre outras atividades que o Arquivo realiza. Fazem usos dos aplicativos que o Twitter proporciona como postar fotos, links, conteúdos multimídiaticos, na intenção de disponibilizar a informação para os seguidores. 
Esse uso, entretanto, é limitado e característico de tipologia dos guias, folders, boletins informativos e outros instrumentos de promoção institucional, utilizados no paradigma tecnicista e custodial de maneira introdutória ao universo de acesso dos APP.

No Paradigma pós-custodial, apontamos, por outro lado, a possibilidade de convergir simultaneamente em ambientes digitais os instrumentos de pesquisa anteriormente utilizados em impressões sobre papel pelos Arquivos, de forma conjunta estruturada pelo DI na Curadoria Digital. Isto é, Guias, Inventários e Catálogos podem ter seus conteúdos liberados das restrições do mundo do papel para atuar potencializando a comunicação, o compartilhamento e a ação cultural.

Para um melhor entendimento do ambiente digital Twitter e do aproveitamento estratégico de seus recursos nos APP exploramos na próxima subseção algumas de suas características.

\section{O TWITTER PARA UMA CURADORIA DIGITAL CONVERGENTE À AÇÃO SOCIAL NOS ARQUIVOS PÚBLICOS PERMANENTES}

Em uma Curadoria Digital pensada para o acompanhamento e participação da comunidade, devem ser consideradas as redes sociais desenvolvidas como comunidades virtuais, criadas por laços de afinidades e/ou amizades.

Assim, a Internet e a Web socializam as mídias que tornam possível a comunicação entre as pessoas, a qualquer hora e lugar, de maneira simultânea e ubíqua. Essas mídias, entre elas as redes sociais se destacam por sua eficiência no compartilhamento das informações para criação de conhecimento atualizado, da construção coletiva de ideias, e da potencialização horizontal da comunicação entre as pessoas.

Sistemas compostos por "nós" e conexões, as redes sociais são representadas por sujeitos sociais (indivíduos, grupos, organizações etc.) no ambiente digital no qual são conectados por algum tipo de relação. Castells (2007, p. 445) afirma que: 
A rede é especialmente apropriada para a geração de laços fracos múltiplos. Os laços fracos são úteis no fortalecimento de informações e na cobertura de novas oportunidades a baixo custo. A vantagem da rede é que ela permite a criação de laços fracos com desconhecidos, num modelo igualitário de interação, no qual as características sociais são menos influentes na estruturação, ou mesmo no bloqueio, da comunicação. De fato, tanto offline quanto online, os laços fracos facilitam a ligação de pessoas com diversas características sociais, expandindo assim a sociabilidade para além dos limites definidos do auto reconhecimento.

Para Recuero, de forma consequente àquela descrita por Castells, as conexões "[...] são constituídas dos laços sociais, que, por sua vez, são formados através da interação social entre os atores" (RECUERO, 2009, p. 30). Esses laços podem ser fortes ou fracos e se definem como:

Laços fortes são aqueles que se caracterizam pela intimidade, pela proximidade e pela intencionalidade em criar e manter uma conexão entre duas pessoas. Os laços fracos, por outro lado, caracterizam-se por relações esparsas, que não traduzem proximidade e intimidade. Laços fortes constituem-se em vias mais amplas e concretas para as trocas sociais, enquanto os fracos possuem trocas mais difusas. (RECUERO, 2009, p. 41).

A criação de tais laços proporciona força às comunidades sociais na Internet, e nela a Web 2.0 ou Web social. É importante notar que nesse contexto, os limites de fronteiras de território foram rompidos, e que a informação se encontra em fluxo contínuo podendo ser atualizada por aqueles que dela desejem se apropriar, com os laços alimentados à distância, por qualquer pessoa, em qualquer lugar do mundo.

As redes sociais na Internet são consolidadas por pessoas que navegam na rede e pelas relações que se criam entre elas, construindo grupos sociais, no mundo virtual. Também de acordo com Recuero (2009, p. 25): "Como partes do sistema, os atores atuam de forma a moldar as estruturas sociais, através da interação e da constituição de laços sociais". Os grupos são formados por afinidades entre os atores (pessoas) e as afinidades podem ser definidas por gostos semelhantes, por grau de parentescos, por amizades feitas fora do mundo virtual, dentre outros elementos que constrói laços de afinidade e de amizade. A autora define as redes como [...] "espaços de interação, lugares de 
fala, construídos pelos atores de forma a expressar elementos de sua personalidade ou individualidade" (RECUERO, 2009, p.26).

Esses espaços de interação são fractais de um espaço universalizante denominado ciberespaço. Nesse universo torna-se fundamental apresentar dados e informações que representem a pessoa, como um nó no sistema complexo, dinâmico que é o ciberespaço. Por meio dessa descrição do perfil, bem como, pela aparência da página na rede social, podem-se inferir gostos e características peculiares do participante da rede, e de seu contexto, o que torna possível a individualização e a personalização da comunicação entre pessoas inseridas em diversas realidades. Recuero (2009, p. 27) assinala que não se trata apenas de uma representação no ciberespaço e sim de apropriações:

Essas apropriações funcionam como uma presença do "eu" no ciberespaço, um espaço privado e, ao mesmo tempo, público. Essa individualização dessa expressão, de alguém "que fala" através desse espaço é que permite que as redes sociais sejam expressas na Internet.

$\mathrm{Na}$ denominada Sociedade da Informação, em que se vive atualmente, as características de apresentação da informação que se fazem presentes no ambiente digital proporcionam oportunidades de crescimento com a socialização da informação pela Web 2.0. Nela, a linguagem escrita associada e hibridizada com outras linguagens, como a imagética, mostra-se de extrema importância para determinação do perfil nas redes sociais, determinando laços fortes e fracos - definidos por Recuero. Entretanto, mesmo que os laços fracos tenham uma relação menos intensa de interação, são os laços sociais fracos os responsáveis pela expansão da rede. O Twitter apropriou-se desse tipo de laço.

As redes sociais, de maneira geral e, especialmente, ambientes como o Twitter, têm sido lugares de comunicação eleitos por jovens, nativos digitais em sua grande maioria, pois "uma das vantagens das redes, tanto para estudantes como para pesquisadores, é a facilidade de poder ler publicações de diversas instituições em um só lugar" (ROMANELLI, 2012, [s. p.]). 
O Twitter foi criado em 2006 e constitui-se como um microblog com capacidade de produzir uma curta mensagem e uma rápida comunicação, pois o limite, até recentemente, era de apenas 140 caracteres. O termo Twitter originou-se de tweet (pio), que em inglês designa o som produzido pelos pássaros, fazendo alusão ao popular "contou-me um pássaro". Twitter, que pode ser traduzido livremente para a língua portuguesa como 'piador', foi pioneiro em serviços de microblogging, seguido por outros como o cocoloop, meme, tumblr, what's up e outros.

Essa modalidade de comunicação por frases rápidas alterou significativamente a formatação das informações para o compartilhamento, principalmente entre os adolescentes, e foi esse o diferencial introduzido pelo Twitter em relação aos demais meios de comunicação da Web Social. Verificamos que o Twitter foi, e ainda é, uma rede social que possibilita o compartilhamento e, ao mesmo tempo, proporciona o acesso à informação de maneira célere, de forma viral, e com escalabilidade, o que, como consequência, reverbera seu alcance a um número significativo de tuiteiros, agentes culturais por excelência. As tecnologias utilizadas pelo Twitter têm aproximado internautas (jovens, estudantes, pesquisadores, etc.) entre si, bem como das instituições.

O Twitter, que como um microblog, inicialmente tinha a característica principal de um serviço de envio de mensagens, para a comunicação direta entre os sujeitos que interagiam por seu intermédio e a produção de informação descentralizada, definia-se, principalmente, pela publicação de textos curtos. A tese de Santaella e Lemos (2010, p. 17) era que:

[...] as SMSs são filhas do e-mail, assim como as pílulas de 140 caracteres do Twitter são filhas das SMSs, com a diferença de que agora essas pílulas adquiriram o caracter populacional dos agenciamentos, de que fala DeLanda. Enquanto os e-mails e as SMSs se limitam a uns poucos agenciamentos, e apenas fazem uso das redes, as mensagens do Twitter não apenas fazem uso das redes, mas criam redes e são também a própria rede.

Historicamente, a plataforma, ambiência, e aplicativo, Twitter, criada por Jack Dorsey e Biz Stone, programadores da empresa Obvious, na Califórnia 
(EUA) partira do SMS (Short Mensage Service), possibilitando a mobilidade informacional. Em fevereiro de 2012, o serviço alcançou 500 milhões de usuários cadastrados, de acordo com a Twopcharts ${ }^{3}$, site especializado em análise de dados de microblogs. Desse número, 33,3 milhões de perfis eram de brasileiros, perfazendo quantidade somente inferior aquela dos Estados Unidos que possuía então 107,7 milhões de usuários no Twitter.

A produção de informação no ambiente partia da pergunta "What are you doing?" (O que você está fazendo?) e com o tempo foi mudada para "What's happening?" (O que está acontecendo?) devido aos novos usos do ambiente. A proposta inicial tinha por objetivo responder à pergunta provocadora, servindose do ambiente como de um micro-diário pessoal. No entanto, as interações entre os sujeitos ampliaram a usabilidade do ambiente para o compartilhamento de informações variadas, de uma miríade de assuntos da vida cotidiana, abarcada posteriormente pelo marketing, jornalismo, política, enfim, para a produção de conhecimento primeiramente de maneira autoorganizada e, posteriormente, por uma profissionalização da ambiência.

O Twitter foi e é, assim, uma mídia social de compartilhamento e criação colaborativa de informação e "[...] a produção de conteúdos de forma descentralizada e sem o controle editorial de grandes grupos econômicos" (ALVES, 2011, p. 97), em que qualquer pessoa pode produzir informação. O Microblogging ocorre quando um produtor de informação escreve, no lugar de um texto longo, atrelado a fotos e vídeos, como ocorre em um blog, uma pequena mensagem, que traz informações breves. O feedback possibilita ver as postagens antigas, potencializando os aspectos conversacionais do ambiente que tem como particularidade uma programação aberta, capaz de propiciar aos colaboradores uma melhoriados serviços oferecidos, bem como de outros aspectos da comunicação: "[...] qualquer usuário que tenha conhecimento de programação de Web, pode contribuir para o site criando

${ }^{3}$ Informação disponível em:http://www1.folha.uol.com.br/tec/1052381-twitter-chega-aos-500milhoes-de-usuarios-diz-site.shtml>. Acesso em: 9 jul. 2012. 
aplicativos, sites de suporte e ferramentas" (RODRIGUES; CARDOSO; MELO, 2009, p. 5).

Coelho (2011, p. 507) coloca que:

O fenômeno de microblogging Twitter é uma rede social diferenciada não só por restringir a quantidade de 140 caracteres para as mensagens de seus usuários, mas também pelo seu caráter mais informacional e uma expectativa maior de feedback simultâneo diante de outras redes, como o Orkut por exemplo.

Com as tecnologias móveis, o Twitter se desenvolveu para acompanhar a mobilidade da rede, onde "[...] o Twitter não é apenas um lugar para difundir suas mensagens. É também um local para se comunicar com outros" (COMM; BURGE, 2009, p. 69). No Twitter,

[...] além de formar as redes pela conversação, é possível formar uma rede de contatos na qual jamais houve qualquer tipo de interação recíproca. E essa conexão, embora não recíproca, pode dar ao ator acesso a determinados valores sociais que não estariam acessíveis de outra forma, tais como determinados tipos de informações. (RECUERO, 2009, p. 83).

A diferença do Twitter em relação às demais redes era, então, seu caráter de rede pública ao dispensar a necessidade de permissão para as pessoas desejosas de seguir as publicações, e ao permitir ainda que alguém obtenha a informação sem ser exatamente um "seguidor". Todavia, Recuero e Zago (2010, p. 70) apontam que "[...] os atores podem configurar suas contas para que eles se tornem de acesso privado", estando às informações visíveis somente para os seguidores permitidos pelo dono do perfil no Twitter.

A partir da limitação dos caracteres, houve a necessidade de se criar meios específicos que fossem propícios à comunicação e à publicação de informação (atualmente um indivíduo que usa o Twitter de forma despersonalizada continua limitado aos 140 caracteres, mas ao personalizar o seu nó na rede ele passa a utilizá-la sem esta restrição).

Por isso, Silva e Valls (2012, p. 139) afirmam que: 
O Twitter possui uma linguagem própria com termos e expressões características, além de ser uma linguagem fluída, própria dos ambientes da Web, no qual as palavras transformam-se em contrações e abreviaturas, que só fazem sentido neste ambiente.

$\mathrm{Na}$ republicação (Retweet) de um tweet utiliza-se o "RT@autor e a mensagem", dando crédito ao autor original do tweet. Comm e Burge (2009, p. 107) assinalam que:

Uma das coisas que faz o Twitter ser uma ferramenta tão poderosa é o fato de que uma informação colocada no site pode rapidamente se espalhar como um vírus. Quando uma pessoa assinala um bom tweet, pode passar essa mensagem para seus próprios seguidores, e logo estará se espalhando por todo o Twitterverso e além.

Nesse contexto, algumas estratégias simples delinearam-se como criações essenciais no universo da organização da informação digital: o uso do RT, por exemplo, tornou-se fundamental para o compartilhamento da informação. Outra solução simples e de convergência eficaz na ambiência digital do próprio tweet possibilita, ao se clicar na ferramenta "expandir" abaixo da postagem, a verificação do número de vezes que a informação foi Retwitada e do número de pessoas que o classificaram como favorito - o que nos permitiu também proceder nossas investigações.

Por outro lado, o uso da hashtags (\#), juntamente a alguma palavra, serve para criar uma etiqueta ou tag, circunscrevendo um universo de assunto comum entre todos os tweets que a utilizam. As etiquetas são utilizadas para marcar a mensagem para posterior recuperação (SILVA; VALLS, 2012). Dessa maneira, a estratégia da etiquetagem ou tageamento, neologismo da cibercultura, tornou-se mais uma forma de organizar as informações e criar conhecimento, paralela às ações praticadas por profissionais da informação, porém, agora de posse da população não especializada.

Além destas características, a comunicação restrita entre as pessoas é também possível no Twitter, como coloca Alves (2011, p. 100): "Os usuários podem trocar mensagens e recados de maneira privada (direct messages) ou pública (replies), fazendo uso é do símbolo @ antes no nome da pessoa a 
quem se dirige o tweet)". O Twitter proporciona, por outro lado, aos que com ele interagem, a possibilidade de postar links, direcionando o interlocutor ao site em que se encontra a informação original. Inicialmente, para que os links pudessem ser exibidos sem o esgotamento do limite, na época da restrição aos 140 caracteres, existiam sites que realizavam o encurtamento de URLs (Uniform Resource Locator) a ser referenciado no Twitter, como o Twitterfeed.

O Twitterfeed possibilitava ainda o registro de uma conta, fazendo que a cada vez que se publicasse uma informação em algum site, essa fosse automaticamente representada por um link registrado no Twitter. A esse respeito, Comm e Burge (2009) esclarecem que o Twitterfeed checa os feeds Rss dos sites (como por exemplo o de um blog). Após essa checagem automática permitida pela interoperabilidade dos sistemas, o Twitterfeed enviava o título e a descrição com um link curto para ser usado no microblog Twitter. Os autores também indicam a existência de outros compressores de endereçamento:

Há uma variedade de diferentes serviços que reduzem as URLs para que você não acabe preenchendo todo o tweet com o endereço de post. Todos eles fazem mais ou menos a mesma coisa, portanto escolhendo TinyURL você mantém o estilo bonito e simples. (COMM; BURGE, 2009, p. 121).

Embora o encurtamento da URL possa ser feito diretamente nos sites de serviços, como o TinyURL, Tweetburner, bit.ly, migre.me, entre outros, no Twitterfeed, tem-se como escolher qual serviço fará o encurtamento das URL.

Também há como postar fotos no Twitter, fazendo-se o upload, ou a subida da imagem, no momento da postagem de um tweet. Para isso, existem outros serviços - convergidos ao próprio Twitter - que facilitam o compartilhamento de fotos, como o Twitpic, TweetPhoto. Para a subida de vídeos, o Twitvid é um serviço que oferece a oportunidade de gravar um vídeo no webcam e publicar, ou ainda de postar vídeos que já estejam gravados no computador, suportando qualquer formato de arquivo. O twiddeo, por outro lado, proporciona o envio de vídeos nos formatos AVI, WMV e JPG salvos em computadores estacionários, notebooks ou celular/smatphone. Outro serviço convergente no Twitter, o twitcam.me, possibilita a produção de vídeos em 
tempo real para seus seguidores, como programas de televisão ao vivo. Destacam-se, além disso, os serviços multifuncionais que compartilham imagens, links, vídeos, filmes e/ou documentos: são o Tweetube, Twi.tt e o tweetlens. Atualmente, o Twitter além oferecer alguns desses serviços já implementados na própria mídia, oferece, também, o encurtamento da URL automaticamente no tweet a ser publicado.

Além disso, convergido ao DI - que pode organizar de maneira estratégica a Curadoria Digital - em associação com os aparatos digitais, dispositivos móveis, redes Wi-Fi, wireless, Bluetooth, smartphones e computadores portáteis, o Twitter demonstrou possibilidades de ampliação e escalabilidade no compartilhamento de informações.

Lançamos, assim, a hipótese de que, as instituições arquivísticas poderiam fazer uso de uma Curadoria Digital e do DI, nela implicado, mais efetiva, eficaz e eficiente para compartilhar informações dos acervos dos APP, e também de outras informações e serviços, agregando em si além das funções disseminadoras e de divulgação de Guias, Inventários e Catálogos, funções educativas e de ação cultural. Assim, para o levantamento dessa hipótese, partimos do princípio que a convergência do $D I$, como disciplina estratégica interdisciplinar da Curadoria Digital, começa no planejamento da construção dos sistemas que serão utilizados pelos APP, por uma equipe multidisciplinar.

Elencamos na próxima sessão, algumas iniciativas que, de acordo com essa hipótese, podem ser replicadas para tornar os ambientes digitais de Arquivos Públicos Permanentes plataformas de comunicação que sejam efetivas na produção compartilhada e coletiva de conhecimento.

\section{INICIATIVAS PARADIGMÁTICAS INTERNACIONAIS E NACIONAIS DO USO DO TWITTER EM AÇÕES DE COMPARTILHAMENTO DA INFORMAÇÃO}

Em uma Curadoria Digital como proposta anteriormente, o DI prevê convergências de linguagens, modelos e interoperabilidade entre sistemas, e 
produção de conteúdo textual, imagético e/ou audiovisual, hibridizados pelas possibilidades dos sistemas em que estão representados.

Uma dessas iniciativas de Curadoria Digital de um evento histórico pelo Arquivo Nacional Britânico foi a narração da Segunda Guerra Mundial, por meio de fontes documentais produzidas pelo Gabinete do Governo, pelas decisões tomadas de Winston Churchill durante a guerra. O perfil dessa narração denominado "War Cabinet" foi criado no Twitter em 2009, tendo suas postagens encerradas em 2015, perfazendo, portanto, a extensão temporal da Segunda Guerra Mundial e restringindo-se ao papel da Grã-Bretanha na contenda. Possuiu 12.194 seguidores do seu perfil, com 8.691 tweets.

Dentre os muitos tweets postados, um dos que continham documentos foi o apresentado na plataforma Twitter. Além das informações que podem ser visualizadas no tweet, por outro lado, a URL encurtada, abaixo da postagem remete 0 internauta ao Arquivo Nacional Britânico, especificamente ao instrumento de pesquisa em que o documento está descrito e representado: o Catálogo. O acesso, portanto, é simultâneo a informação, dados e metadados.

As outras iniciativas resultantes de nossa investigação exploratória não foram realizadas por instituições arquivísticas, mas configuram também ações de Curadoria Digital que podem ser replicadas. A iniciativa do estudante da Universidade de Oxford, Alwyn Collinson, narrou a Segunda Guerra Mundial com um viés diferente do Gabinete do Governo Britânico. O autor procura narrar evidenciando como as pessoas viviam (ou morriam) mediante a guerra. Isto é, busca uma narrativa de baixo para cima, menos oficial e mais ampliada que a narrativa do Arquivo Nacional Britânico, mostrando com profundidade os horrores da Segunda Guerra Mundial, como, por exemplo, o holocausto.

O perfil dessa narração, “@RealTimeWWII”, iniciou-se em 2011 no Twitter, e terminou em 2016. O perfil possuiu 332.149 seguidores.

Collinson iniciou a narração com alguns livros de autoridade, como o "Inferno: A Guerra Mundial, 1939-1945", outros, encontrados na Web. Com o passar do tempo, os seguidores indicavam fontes, como diários de guerra de parentes postados em blogs, jornal polonês descrevendo o assassinato contra 

curadoria digital

Hitler de 1939, arquivos de jornais digitalizados, transcrição de discursos, histórias pessoais ${ }^{4}$. Os tweets são acompanhados de imagens da Segunda Guerra Mundial, recuperadas nessas fontes na Web. Essas imagens, muitas vezes, são retuitadas pelos seguidores. A partir do "Retweets" é possível perceber o potencial de disseminação da informação no Twitter. Para tanto, selecionou-se um tweet, em que chamou a atenção pela quantidade de "Reweets" feitos pelos seguidores. Um tweet com a imagem de um mapa dos EUA foi retuitado 695 vezes.

Para seguir a trilha desses tweets, procuramos por alguns seguidores que retuitaram a informação original. Os três primeiros seguidores, dos 695 seguidores desse tweet, possuíam, por sua vez, uma quantidade significativa de outros seguidores em suas páginas no Twitter; o seguidor $\mathbf{A}$ do perfil RealTime, retuitou o tweet para sua página, e automaticamente 1.202 seguidores acessaram a informação. $\mathrm{O}$ seguidor $\mathbf{B}$, do RealTime, retuitou o tweet para sua página e 484 pessoas (seus seguidores) visualizaram a publicação. O seguidor C, também do RealTime, retuitou o tweet para sua página e 1.822 pessoas (seus seguidores) visualizaram essa publicação. Observamos, portanto, que, além dos seguidores que em 2012, perfaziam o número de 263.977 com um laço forte, mais de 3.508 internautas viram indiretamente o tweet, a partir dos três (03) seguidores que acompanhamos, dentre os 695. Assim, em nossa amostra, três (03) pessoas ao retuitarem o conteúdo de informação criaram uma multiplicação exponencial de 3508 reproduções de um tweet, dentre os 4.406 tweets publicados no ambiente digital na época.

No Brasil, verificamos uma iniciativa semelhante, realizada pelo Diário Catarinense, que narrou o evento histórico "Tomada da Laguna", um dos eventos da Revolução da Farroupilha, iniciada em 2 de Junho e estendida até 15 de novembro de 2011: dez personagens do evento histórico ganharam

\footnotetext{
${ }^{4}$ A BBC pediu ao público a contribuir com suas memórias da Segunda Guerra Mundial para um site entre Junho de 2003 e Janeiro de 2006. Este arquivo de 47.000 histórias e 15.000 imagens é o resultado. Disponível em: http://www.bbc.co.uk/history/ww2peopleswar/. Acesso em: 06 nov. 2012.
} 
perfis no Twitter, para a narração, entre eles Giuseppe Garibaldi, Anita Garibaldi, Bento Gonçalves, David Canabarro, Marujo Luidi Carniglia, Antônio Netto, Presidente de Santa Catarina, Coronel Villas Boas, Imprensa 1839 e o Diário Catharinense. Além dos tweets postados nesses perfis, também era possível, durante a vigência do projeto, visualizar documentos produzidos por vários atores da Revolução Farroupilha. Contudo, com a finalização desse projeto, muitos documentos históricos utilizados foram retirados da plataforma do Twitter, permanecendo apenas uma imagem, que é a casa da Anita Garibbaldi.

A responsável das atualizações diárias na rede foi à jornalista do Diário Catarinense Juliana Sakae, que revelou ter a ideia surgido em discussões com Bárbara Nikel, editora de mídias sociais do grupo RBS. Esta the mostrou algumas iniciativas, como o "Evangelho segundo o Twitter", The "Washington Post" e a iniciativa de fazer algo criativo. Nakae "explicou que as postagens foram todas baseadas em documentos históricos (buscados na Coleção Wolfgang Rau, Arquivo Histórico do Município de Florianópolis, Arquivo Público do Estado de Santa Catarina e na Biblioteca Pública Municipal Professor Romeu Ulysséa)" (ARQUIVO..., 2011).

Finalmente, essas verificações nos levaram a considerar que na rede social Twitter há uma visível fractalidade na complexa circulação da informação e um grande potencial de compartilhamento da informação entre as pessoas que se comunicam por meio dessa rede social.

\section{CONSIDERAÇÕES}

Como se pôde verificar pelos abreviados relatos anteriores, são muitas as estratégias potencialmente oferecidas aos internautas que acessam o ambiente do Twitter, bem como, aos profissionais da informação que, responsáveis por uma Curadoria Digital pensada do ponto de vista do $D \mathrm{I}$, podem utilizá-las de maneira estratégica, convergindo a interação nessa rede social para o compartilhamento de informação de gêneros diferenciados e, durante esse processo, construir conhecimento coletivo, em ações culturais 
criadas a partir dos ambientes digitais de Arquivos Públicos Permanentes: "O Twitter coloca nas mãos dos usuários (sic) o poder de transmitir e apropriar-se da informação de maneira nunca antes ocorrida na história" (ALVES, 2011, p. 103). Embora questionemos a terminologia "usuários", pertecente ao paradigma tecnicista e custodialista, concordamos com Alves.

A convergência do ambiente do Twitter em Unidades de Informação, principalmente nos APP, e em especial, nos serviços culturais que estes podem prestar, amplia e reverbera as potencialidades de criação de conhecimento, a partir de uma estratégica Curadoria Digital apreendida pelos profissionais da informação responsáveis pela criação e cura dos conteúdos dos seus ambientes digitais.

Para a consolidação da Sociedade da Informação, de acordo com o paradigma pós-custodial de acesso, o uso do Twitter nos APP é, assim, decisivo para a interação com os indivíduos que buscam a informação, para conquistar novos interlocutores e propiciar a geração de laços sociais entre indivíduos que se tornem atores da rede.

Em relação à recuperação de informação, em nossa pesquisa exploratória verificamos que, a convergência da plataforma do Twitter nos ambientes digitais dos Arquivos Públicos Permanentes torna também desnecessária a busca de informação de caráter histórico cultural em Websites dispersos, pois o Twitter pode ser agregado em função de convergir conteúdos informacionais diversificados para que sejam acessados em um só lugar de informação: a página da instituição criada no Twitter. A pessoa que busca as informações pode acessá-las de maneira ativa, por suas necessidades ou ainda ser convidado a participar da rede Twitter do APP. Recomenda-se, nesse sentido, que uma equipe multidisciplinar constituída de profissionais da informação preparados, com noções da disciplina DI, para a Curadoria Digital nos APP atue no sentido de realizar um compartilhamento da informação eficaz, eficiente e efetivo. Para que essa hipótese seja uma realidade, demonstramos, por meio dos resultados de nossa investigação exploratória, que a mídia social Twitter pode ir além de publicações referentes a produtos e serviços presentes na instituição. Pode oferecer aos APP, por exemplo, a 
possibilidade de trabalhar com a publicação de documentos históricos selecionados, concomitantemente à narração de eventos de integração, criando dessa maneira um acervo digital com organização diversa daquele que está fisicamente custodiado na instituição e que deve respeitar o principio da proveniência. Os simulacros digitais podem, por outro lado ser reorganizados em inúmeros conjuntos, perfazendo um maior número de leituras.

As ações descritas como de Curadoria Digital conceituada e executada por meio da interatividade e convergência com o Design da Informação, constituem a natureza pós-custodial das atuações dos profissionais da informação nos ambientes dos Arquivos Públicos Permanentes. É importante, destacar que, dessa maneira, o termo pós-custodial refere-se a uma categoria temporal e a ele podemos conjugar outras nomenclaturas e conceitos, entre eles os de custódia ampliada e hiper-custodia, cujas categorias não são temporais, mas referem-se à uma qualidade extensiva da ação de custódia. Esperamos, com os resultados de nossa pesquisa teórico exploratória, ter contribuído para um melhor entendimento dessas confluências contemporâneas.

\section{REFERÊNCIAS}

ABBOUT, D. What is digital curation? Digital Curation Centre, Edinburgh, 2008. Disponível em: <http://www.dcc.ac.uk/resources/briefing-papers/introductioncuration/what-digital-curation\#1>. Acesso em: 20 dez. 2011.

ARQUIVO Café História. Proclamada no Twitter a revolução farroupilha. [S.I.], 2011. Disponível em: <http://cafehistoria.ning.com/profiles/blogs/arquivo-cafe-historia75>. Acesso em: 12 set. 2011.

ALVES, C. D. Informação na twitosfera. Dig. Bibl. Ci. Inf., Campinas, v. 9, n.1, p. 92105, jul./dez. 2011. Disponível em:

<http://143.106.108.14/seer/ojs/index.php/sbu rci/article/view/497 >. Acesso em: 15 fev. 2012.

CASTELLS, M. A sociedade em rede. 10. ed. totalmente rev. ampl. São Paulo: Paz e Terra, 2007. (A era da informação: economia, sociedade e cultura, v. 1).

COELHO, T. F. Twitter: como uma nova mídia modificou a rotina produtiva de jornalistas em Teresina. In: CONGRESSO NACIONAL LITERACIA, MEDIA E CIDADANIA, 1., 2011, Braga. Anais... Braga: Universidade do Minho, 2011. p. 505- 
Maria José Vicentini Jorente; Lucineia da Silva Batista

Conversações entre a rede social twitter e os arquivos permanentes: um estudo de curadoria digital

513. Disponível em: <http://www.lasics.uminho.pt/ojs/index.php/lmc/article/view/487> . Acesso em: 15 jun. 2012.

COMM, J.; BURGE, K. O poder do Twitter: estratégias para dominar seu mercado e atingir seus objetivos com um tweet por vez. Tradução Leonardo Abramowicz. São Paulo: Editora Gente, 2009.

CRUZ MUNDET, J. R. Manual de archivística. Madrid: Fundación Germán Sánchez Ruipérez, 2001.

GONÇALEZ, P. R. V. A. Disseminação da informação nos websites das instituições de patrimônio público: um enfoque nos arquivos permanentes. 2013. 144 f. Dissertação (Mestrado em Ciência da Informação)-Faculdade de Filosofia e Ciências, Universidade Estadual Paulista, Marília, 2013.

HIGGINS, S. The DCC Curation life cycle model. The International Journal of Digital Curation, Edinburgh, v. 3, n. 1, 2008. Disponível em: <http://www.ijdc.net/>. Acesso em: 15 jun. 2012.

RECUERO, R. Redes sociais na internet. Porto Alegre: Editora Sulina, 2009. Disponível em:

<http://www.pontomidia.com.br/raquel/arquivos/redessociaisnainternetrecuero.pdf>. Acesso em: 23 fev. 2012.

RECUERO, R.; ZAGO, G. "RT, por favor": considerações sobre a difusão de informações no Twitter. Revista Fronteiras, São Leopoldo, v. 12, n. 2, p. 69-81, maio/ago. 2010. Disponível em: < http://www.fronteiras.unisinos.br/pdf/88.pdf >.

Acesso em: 24 fev. 2012.

RODRIGUES, A.; CARDOSO, L. M.; MELO, L. O Piauí no twitter: o perfil do usuário da plataforma no estado. In: CONGRESSO DE CIÊNCIAS DA COMUNICAÇÃO NA

REGIÃO NORDESTE, 11., 2009, Teresina. Anais... Teresina: Intercom, 2009. p. 1-14. Disponível em:

<http://www.intercom.org.br/papers/regionais/nordeste2009/resumos/R15-0315-1.pdf>. Acesso em: 17 mar. 2012.

ROMANELLI, C. Redes sociais caem no gosto de estudantes e pesquisadores: cada vez mais, arquivos públicos disponibilizam seus acervos online, ao mesmo tempo em que amantes da História desenvolvem ferramentas de ensino para estudantes e curiosos na web. Revista de História.com.br, Rio de Janeiro, 1 out. 2012. Disponível $\mathrm{em}:<$ http://www.revistadehistoria.com.br/secao/em-dia/historia-com >. Acesso em: 12 nov. 2012.

SANTAELLA, L.; LEMOS, R. Redes sociais digitais: a cognição conectiva do Twitter. São Paulo: Paulus, 2010.

SAYÃO, L. F.; SALES, L. F. Curadoria Digital: um novo patamar para preservação de dados digitais de pesquisa. Inf. \&Soc., João Pessoa, v.22, n.3, p. 179-191, set./dez. 2012. Disponível: em: $<$ https://www.icict.fiocruz.br/sites/www.icict.fiocruz.br/files/Curadoria\%20digital Luis \%2 0Fernando\%20Sayao.pdf>. Acesso em: 26 mar. 2016. 
Maria José Vicentini Jorente; Lucineia da Silva Batista

Conversações entre a rede social twitter e os arquivos permanentes: um estudo de curadoria digital

SIEBRA, S. A. et al. Curadoria digital: além da questão da preservação digital. IN: ENCONTRO NACIONAL DE PESQUISA EM CIÊNCIA DA INFORMAÇÃO, 14., Florianópolis. Anais eletrônico... Florianópolis: UFSC, 2013. Disponível em: $<$ http://www.egov.ufsc.br/portal/sites/default/files/curadoria digital $0 . p d f>$. Acesso em: 26 mar. 2016.

SILVA, H. S.; VALLS, V. M. Retenção de conhecimento na internet: o papel do Twitter. CRB-8 Digital, São Paulo, v. 1, n. 5, p. 124-147, jan. 2012. Disponível em: <http://revista.crb8.org.br>. Acesso em: 14 jul. 2012.

TWITTER chega aos 500 milhões de usuários, diz site. Folha de S. Paulo, São Paulo, 23 fev. 2012. Disponível em: < http://www1.folha.uol.com.br/tec/1052381-twitter-chegaaos-500-milhoes-de-usuarios-diz-site.shtml >. Acesso em: 9 jul. 2012.

Title

Conversations between Twitter social media and historical archives: a digital curation study

\begin{abstract}
Introduction: Digital Curation, in post-custodial times, convergent to Information Design, propose curation strategies; among the steps to be performed, is the interaction. Twitter helps with this approach and communication, facilitates information sharing as well as enables the storytelling Curation. Objective: To present innovative Digital Curation initiatives in Twitter and its potential to share information preserved by Public Historical Archives. Methodology: We characterize it as a theoretical and exploratory research on the application of Twitter in the perspective of Digital Curation, interdisciplinary to Information Science. Ten public historical archives were analyzed, in which their convergence with Twitter was verified; and an investigation of two archives profiles to identify their contents was conducted. Finally, initiatives to narrate historical events are presented. Results: Twitter offers Archives the possibility to work on historical event narratives; simultaneously publish on the platform the basic documents of the narration and build a diverse digital collection of what is physically kept by the institution. Conclusions: Actions described in Digital Curation are the activities of postcustodial nature information professionals perform in Archives. We emphasize that the post-custodial term consists of a temporal category and we can add the concept of extended custody, which is not temporal, but of extension.
\end{abstract}

Keywords: Information technology and communication. Information design. Digital curation. Historical archives. Twitter.

\title{
Título
}

Conversaciones entre Twitter social media y historical archives: un estudio de Curación Digital 
Maria José Vicentini Jorente; Lucineia da Silva Batista

Conversações entre a rede social twitter e os arquivos permanentes: um estudo de curadoria digital

\section{Resumen}

Introducción: La Curación Digital, en tiempos postcustodiales, convergente al Diseño de la Información, propone estrategias de curación; Entre los pasos a realizar, está la interacción. Twitter ayuda con este enfoque y la comunicación, facilita el intercambio de información, así como permite la Curación de narraciones de historias. Objetivo: Presentar iniciativas innovadoras de Curación Digital en Twitter y su potencial para compartir información preservada por Archivos Históricos Públicos. Metodología: La caracterizamos como una investigación teórica y exploratoria sobre la aplicación de Twitter en la perspectiva de la Curación Digital, interdisciplinaria a la Ciencia de la Información. Se analizaron diez archivos históricos públicos, en los que se verificó su convergencia con Twitter; y se realizó una investigación de dos perfiles de archivos para identificar su contenido. Finalmente, se presentan iniciativas para narrar acontecimientos históricos. Resultados: Twitter ofrece a los Archivos la posibilidad de trabajar en narraciones históricas de eventos y, simultáneamente, publicar en la plataforma los documentos básicos de la narración y construir una colección digital diversa de lo que es físicamente mantenido por la institución. Conclusiones: Las acciones descritas en la Curación Digital son las actividades de los profesionales de la información de naturaleza postcustodial que realizan en Archivos. Hacemos hincapié en que el término postcustodial consta de una categoría temporal y podemos añadir el concepto de custodia extendida, que no es temporal, sino de extensión.

Palabras clave: Tecnología de la información y comunicación. Diseño de la información. Curación digital. Archivos históricos. Twitter.

Recebido: 12.02 .2016

Aceito: 25.03.2017 